\title{
UNIVERSIDADES ABERTAS A TERCEIRA IDADE: delienando um novo espaço educacional para o idoso
}

\author{
Rita de Cássia da Silva Oliveira ${ }^{1}$ \\ Paola Andressa Scortegagna ${ }^{2}$ \\ Flávia da Silva Oliveira ${ }^{3}$
}

\begin{abstract}
RESUMO
Atualmente um dos grandes desafios da sociedade mundial é o envelhecimento da população que tem provocado mudanças significativas no desenho demográfico apresentando diferentes demandas para esta parcela da população que cresce vertiginosamente. As universidades enquanto instituições baseadas nos tripé de ensino, pesquisa e extensão oportunizam diferentes intervenções na área da educação, Este artigo resulta de uma pesquisa bibliográfica sobre a temática, sob o recorte da educação. Tem como objetivo refletir sobre a educação para o idoso, a educação permanente, uma revisão histórica sobre o surgimento das atividades educacionais voltadas para os idosos na sociedade brasileira. Objetiva também a explanação sobre o surgimento da gerontologia como ciência e área de estudo/pesquisa; aborda a história da criação e implementação da Universidade Aberta para a Terceira idade (UATI) na Universidade Estadual de Ponta Grossa, explicitar os objetivos e a estrutura da UATI enquanto Programa extensionista na UEPG. A UATI/UEPG oferece diferentes atividades aos idosos, distribuídas em quatro grandes eixos: saúde, nutrição e qualidade de vida; educação, cultura e arte; educação, esporte e lazer; direito, empoderamento e cidadania. A UATI volta-se para a valorização do idoso, possibillitar a aquisição de conhecimentos, informação e atualização do idoso, proporcionar uma melhoria na qualidade de vida desta faixa etária e, como decorrência a elevação da auto estima, empoderamento, maior participação e inserção social do idoso. A UATI apresenta benefícios aos idosos que a frequentam, comprovado pelo sucesso e reconhecimento social nestes 24 anos de atividades.

Palavras-chave: Educação para o idoso; Universidade Aberta para a Terceira Idade; Extensão; Gerontologia; Políticas Públicas.
\end{abstract}

\section{UNIVERSITIES OF THE THIRD AGE: outlining a new educational space for the elderly}

\begin{abstract}
Currently one of the major challenges of global society is the aging of the population has caused significant changes in the demographic drawing with different demands for this population grows dramatically. Universities as institutions based on teaching tripod, research and nurture different interventions in education. This article results from a literature search on the subject, under the focus of education. Aims to reflect on education for the elderly, lifelong learning, a historical review of the emergence of educational activities for the elderly in Brazilian society. Also aims at the explanation of the emergence of gerontology as a science and study / research area; covers the history of creation and implementation of the Open University for the Third Age (Universidade Aberta para a Terceira Idade - UATI) in Universidade Estadual de Ponta Grossa, explain the goals and structure of the UATI as extension program at UEPG. The UATI / UEPG offers different activities for older people, divided into four areas: health, nutrition and quality of life; education, culture and art; physical education, sports and leisure; rights, empowerment and citizenship. The UATI turns to the appreciation of the elderly, enables the acquisition of
\end{abstract}


knowledge, information and updating the elderly, provides an improved quality of life for this age group and, as a result raising the self-esteem, empowerment, greater participation and inclusion social of the elderly. The UATI provides benefits to seniors who attend as evidenced by the success and social recognition in these 24 years of activities.

Keywords: Education for the elderly. Open University for the Third Age. Extension. Gerontology. Public policy.

\section{INTRODUÇÃO}

A educação é um fenômeno de grande complexidade, pela própria etimologia da palavra, se por um lado educação significa desenvolver as habilidades e potencialidades do indivíduo de dentro para fora, por outro lado, de fora para dentro, a sociedade deve oferecer as oportunidades e condições para o desenvolvimento pleno do indivíduo.

Caracterizando-se como um fenômeno essencialmente humano, a educação reflete o indivíduo como integrante de uma sociedade num tempo e espaço determinados, enquanto também contribui na formação deste mesmo indivíduo fundamentado nas ideologias dominantes e na concepção de homem e de mundo que naquele momento prevalece.

Não se constitui em um fenômeno isolado, mas a educação é um processo contínuo, um fato existencial e social (PINTO, 1989). Além de ocorrer em sociedade, como fenômeno cultural não proporciona formação uniforme a todos os indivíduos porque é sustentada por uma ideologia, com finalidade estabelecida, inserida em um contexto sócio econômico, em um dado tempo histórico.

A educação tem um caráter permanente, é uma prática política e persiste em todos os lugares nos quais o homem vive, não sendo responsabilidade apenas de uma instituição, a escola, mas media o homem na própria constituição de se tornar humano, no cotidiano, nas relações que ele estabelece, na família e na sociedade, num sentido micro e macro.

A educação acontece ao longo da vida, de maneira permanente e não existe um único modelo de educação. Assim, pode-se sistematizar a educação em modalidades informal, formal e não formal.

Nesta busca da constituição do homem social, a educação varia nas diferentes etapas da vida humana: infância, adolescência, idade madura e velhice. As políticas educacionais, a concepção que se tem de homem e de mundo estabelecessem os objetivos, as metodologias, os interesses, as percepções, a formação de educadores, os financiamentos, definindo até o grau de interesse de apoio em pesquisas realizadas.

Enquanto etapa de vida daqueles que atingem a longevidade, a velhice é uma construção social. Em determinadas sociedades é percebida como sinônimo de aspectos positivos e otimistas, envolvendo respeito, sabedoria, qualidade de vida, valorização, mas contraditoriamente, também é vista de forma negativa e marginalizadora, sendo a ela atribuída qualidades como discriminação, alienação, incapacidade, violência. Entre uma e outra visão, aparece o homem nesta faixa etária como detentor da sabedoria e do conhecimento, mas podendo ser considerado também sob outro aspecto como improdutivo e incapaz de contribuir com a sociedade.

Essa dicotomia de percepção da velhice também é um reflexo da cultura de uma sociedade na qual a educação é um instrumento relevante que contribui para determinar uma ou outra concepção social. 
Na sociedade capitalista, a educação para os idosos por muitos anos foi negada baseada nessa ideia de incapacidade do idoso para aprendizagem, reforçada por uma visão estereotipada e pessimista da velhice, ligada a incapacidade, improdutividade, doença, desatualização e que economicamente não compensa investimento educacional nesta faixa etária.

Entretanto, entre os estudiosos sobre o tema é consenso a necessidade de uma mudança cultural na sociedade brasileira, sendo o idoso e a velhice temáticas principais, mas para isso, é importante uma educação para o envelhecimento, na qual seja reconhecida a relevância do idoso enquanto ator social e que prescreva uma educação para o envelhecimento com perspectivas mais otimistas.

Como bem afirma Saviani (1991), a educação é uma pratica social e é justamente entre as reflexões/teoria e as ações/prática que irá se construir uma nova visão de idoso.

O idoso, com essa visão mais otimista, passa a exigir seus direitos como cidadão, entre os quais está a educação.

As Universidades Abertas a Terceira Idade tem-se disseminado ao longo das últimas décadas e se configurado como uma tendência mundial. São espaços educacionais criados em instituições de ensino superior, considerando o idoso como protagonista de direitos e deveres.

Desta maneira, a educação na terceira idade tornou-se uma temática relevante e necessária dentro do estudo da gerontologia. E, são alguns aspectos da educação para o idoso que se pretende expor a seguir e levá-lo a reflexão conjunta, porque enquanto se pensa sobre o assunto, também se envelhece.

\section{EDUCAÇÃO PARA O IDOSO}

A educação entendida enquanto prática social possibilita ao homem uma aprendizagem ao longo da vida, favorecendo uma transformação cultural e da própria sociedade.

Ao desempenhar o seu papel democrático, de compartilhamento de saberes, de experiências, possibilita a cada indivíduo conscientizar-se do mundo e do papel que desempenha dentro deste contexto social no qual faz parte.

De acordo com Freire (1979, p.27), “a educação é uma resposta da finitude da infinitude", pois todo sujeito é inconcluso, e por meio de processos educacionais irá encontrar meios para suprir sua constituição inacabada, independente de sua idade, raça ou condição socioeconômica.

Refletindo-se sobre a educação enquanto ação permanente e sobre os processos de aprendizagem, que ocorre ao longo da vida, não representa apenas uma evolução do pensamento pedagógico, mas faz referência a necessidade de constante atualização, num mundo globalizado no qual as mudanças são rápidas e contínuas, permitindo que os sujeitos evoluam segundo estes princípios (1999).

De acordo com Pinto (1989) a educação não é uma conquista de cada indivíduo, mas se constitui como uma função da sociedade e está diretamente ligada ao grau de desenvolvimento que a sociedade apresenta. Desta maneira, considera-se que a educação é permanente porque embora em diferentes graus sempre está presente na sociedade.

Conforme aponta Zaias (2012), a educação permanente se refere a aprendizagem necessária para o desenvolvimento das competências das pessoas, nas mais diversas condições. Com a evolução tecnológica, há a necessidade de adaptação à tais condições, o que pressupõe uma educação permanente.

Gadotti (1984, p.69) aponta que, "a educação permanente visa uma educação rearranjada, refletida e integrada no seu todo. Ela sustenta a ideia de um controle de todos 
os recursos educativos possíveis de uma sociedade e de sua execução". A educação, entendida como um processo permanente na vida do indivíduo, instrumentalizando-o com conhecimentos, possibilita atualização, oferece informações para maior inserção e participação social, possibilita desenvolver habilidades que além de valorizar o idoso, propicia o empoderamento, preparando-o para desempenhar novos papéis, pela elevação da sua autoestima, valorização pessoal, familiar e social.

Para Freire (1997, p.20) "A educação é permanente na razão, de um lado, da finitude do ser humano, de outro, da consciência que ele tem de sua finitude".

Assim, a educação, além de ser um direito social básico e elementar, representa também o caminho, ou a condição necessária, que vai permitir o exercício e a conquista do conjunto dos direitos e deveres da cidadania, que se ampliam a cada dia em contrapartida às necessidades do homem e da dignidade humana.

Nas legislações referentes aos idosos, observa-se que a educação está presente. No artigo terceiro da Política Nacional do Idoso (1994), Lei 8.842/94, propõe-se a melhoria das condições de estudo para que os idosos possam aprender com mais facilidade, criando programas específicos, além de educar a população para melhor entender o processo de envelhecimento.

Segundo o Estatuto do Idoso (2003), Lei 10.741/03, no Capítulo 5, nos artigos 20 ao 25, estabelece-se que o idoso tem direito à educação, respeitando a peculiar condição de sua idade. O Poder Público criará oportunidades de acesso do idoso à educação, havendo cursos especiais para que o mesmo integre-se à vida moderna, além de apoiar a criação de universidade aberta para as pessoas idosas e publicações de livros e periódicos com conteúdos adequados a esta população.

No texto base da $2^{\text {a }}$ Conferência Nacional dos Direitos da Pessoa Idosa, a educação é vista como "uma categoria associada à capacidade de oportunizar desenvolvimento pessoal, transformação e mudança social, além de qualificação para o trabalho e para vida coletiva" (2008, p.31). No mesmo texto, a educação considerada como política pública para o envelhecimento está amparada pelas Leis 8.842/94 (Política Nacional do Idoso) e 10.741/03 (Estatuto do Idoso). A educação encontra apoio na cultura, a qual "expressa a totalidade das experiências materiais e simbólicas adquiridas e acumuladas pelas pessoas ao longo da vida e revela os comportamentos apreendidos no aprendizado social(2008, p.32).

A inserção de idosos em espaços educativos que promovam a integração e uma educação de qualidade para este público é prevista em diversas políticas, porém, se observa que aquilo que está prescrito ou recomendado muitas vezes não está sendo cumprido. As ações governamentais para o idoso voltam-se na maioria das vezes para questões de saúde e da própria previdência, alegando-se poucos recursos para outras ações.

Refletindo sobre a educação para este grupo etário, além do entendimento dos pressupostos legais, existe a necessidade de compreender os processos educacionais para o idoso.

As discussões em relação à educação para o idoso, especificamente na gerontologia educacional são recentes, fator que incide na limitação de obras específicas e um número ainda pequeno de pesquisas na área.

A gerontologia educacional surgiu na década de 1970, nos Estados Unidos, como segmento da gerontologia. Naquele momento, a gerontologia surgiu como disciplina no curso de psicologia clínica da Universidade de Nebraska, a qual estava organizando um dos primeiros departamentos de gerontologia em espaços acadêmicos. O termo foi criado por David Peterson, o qual foi professor responsável pela disciplina por cerca de 5 anos naquela universidade. Em 1978, o professor Peterson transferiu-se para a Universidade do 
Sudeste da Califórnia, na qual atua até hoje em pesquisas envolvendo a gerontologia educacional (2012).

As pesquisas acerca da gerontologia educacional começaram a se estabelecer no início da década de 1980 em outros países, destacando-se a Espanha, com vários autores que voltaram seus estudos à educação de idosos (MARTín GARCÍA, 1994). No Brasil, a gerontologia educacional começou a ser estudada na década de 1990.

A gerontologia educacional enquanto disciplina científica assume uma dupla dependência epistemológica: por um lado a pedagógica, voltada para a pedagogia social e educação de adultos e, por outro lado a gerontológica, apoiada fundamentalmente na gerontologia social. O desenvolvimento da gerontologia educacional se alicerça na concepção, elaboração e implementação de programas de animação, estimulação, enriquecimento pessoal, formação e instrução dirigidos aos idosos. Dessa maneira, congrega todas as atividades educativas em que participem os idosos.

A partir dos anos 2000, percebe-se um aumento significativo nas pesquisas envolvendo a gerontologia educacional, representando um salto qualitativo neste campo. Houve um aumento expressivo de produções científicas, porém ainda há necessidade de novos enfoques e de maior aprofundamento teórico da área.

A gerontologia educacional é um campo de estudo e prática que tem por objetivo a educação para e sobre a velhice e o envelhecimento. Inclui duas dimensões (teórica e prática), tendo o idoso como protagonista (1976):

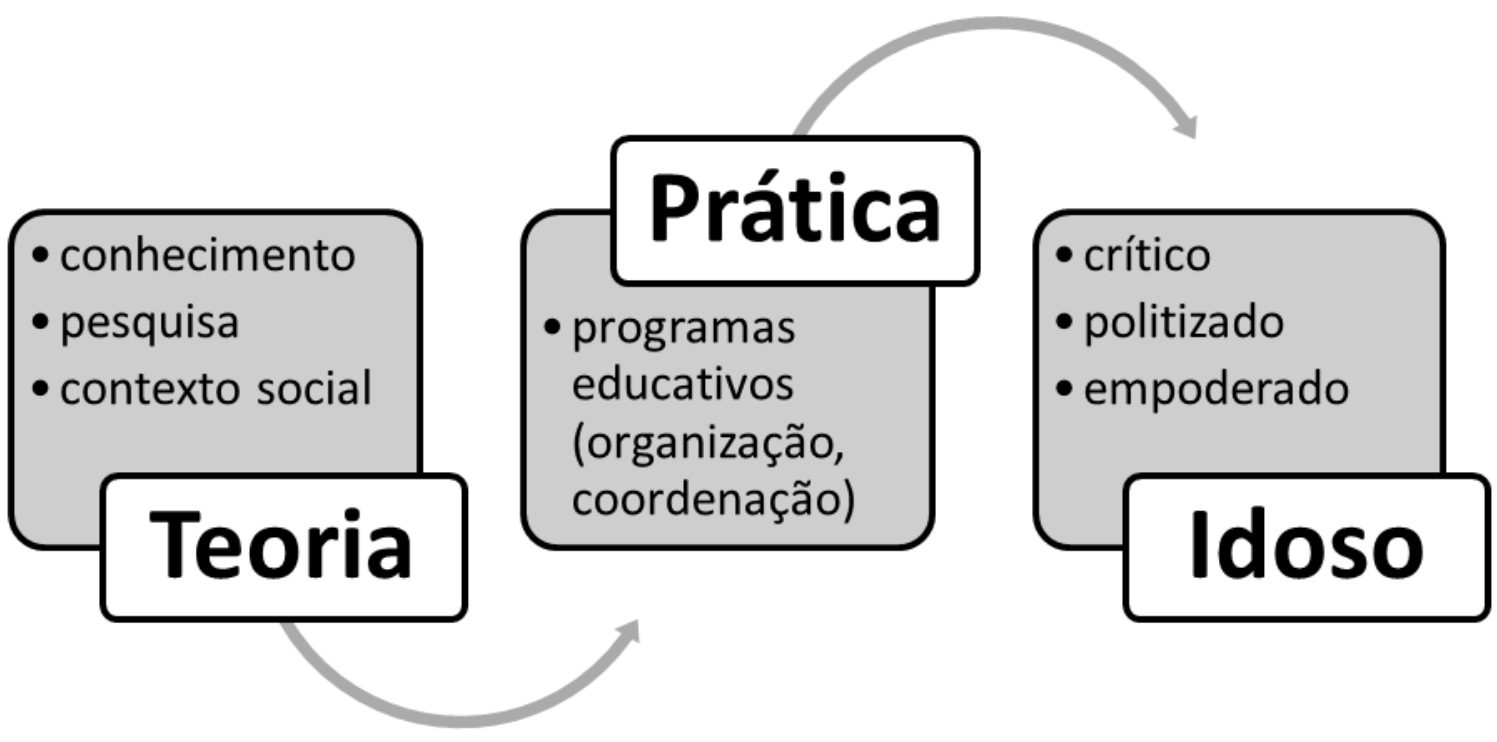

Figura 1. Atuação da Gerontologia Educacional Fonte: Peterson, 1976, p.61-73

Por meio da atuação da Gerontologia Educacional, há a medicação pelo diálogo, pelo compartilhamento de ideias, em uma construção coletiva de saberes, e nessa concepção os envolvidos incorporam os conhecimentos como forma de empoderamento. A compreensão da realidade é imprescindível para a contextualização da prática social e a efetiva participação.

$\mathrm{O}$ processo de empoderamento possibilita atuar sobre as situações de vulnerabilidade e exclusão, possibilitando o aumento de poder daqueles grupos mais desprovidos. De acordo Vasconcelos (2001, p.5) empoderamento conceitua-se como "o aumento do poder pessoal e coletivo de indivíduos e grupos sociais nas relações 
interpessoais e institucionais, principalmente daqueles submetidos a relações de opressão e dominação social".

Neste sentido, Kleba e Wendausen (2009) afirmam que as relações de poder não podem ser consideradas como estabelecidas, pré-determinadas, mas possuem flexibilidade e, sofrem mudanças, a medida que ocorre, por parte de cada indivíduo, a conscientização da própria realidade em que estão inseridos e, embora existam relações conflituosas e de poder, existe também a possibilidade de intervenção na sociedade pelas ações dos homens.

A participação social deve ser entendida como direito de todos os sujeitos, caracterizando-os como cidadãos, independentemente de classe social, raça, gênero ou faixa etária. $\mathrm{O}$ direito a inserção social deve ser preservado em todas as situações, para todas as pessoas que compõe a sociedade brasileira. Apesar de culturalmente o respeito à dignidade humana não ser encarado como direito de todos no Brasil, a partir do momento em que cada vez mais grupos minoritários começarem a se mobilizar, novos conceitos culturais poderão ser formados.

Conhecer os próprios direitos é preceito elementar para que se reclame melhores condições de sobrevivência e uma melhor qualidade de vida, entretanto para viabilizar essas atitudes por parte dos idosos, a educação surge como mediadora a qual instrumentaliza os idosos com conhecimentos e informações para que assumam a posição de reivindicação de maior reconhecimento e espaço social.

Nestes condicionantes, a educação apresenta-se como propulsora da transformação social, pois é através dela que além da aquisição de conhecimentos, o processo de socialização se intensifica, e a formação de um sujeito crítico e reflexivo se consolida.

A valorização da sabedoria do idoso e respeito às suas experiências surge como necessidade premente na representação social do idoso e na distribuição mais equitativa do poder, possibilitando uma perspectiva de rompimento com a discriminação generalizada atribuída a este segmento.

Podem-se distinguir quatro formas básicas de poder: cultural, social, político e econômico. Estas diferentes roupagens assumidas pelo poder não se excluem, ao contrário, se complementam e beneficiam no seu conjunto o progresso do indivíduo, da família ou do grupo. Compete a cada um dos grupos sociais promover o seu próprio desenvolvimento, entendendo que desenvolvimento é a distribuição mais equilibrada do poder entre os indivíduos na sociedade. Porém, há grupos que estão à margem do poder e que necessitam de apoio para empoderar-se.

O poder pode ser entendido no sentido de transformação social, entre aqueles que detém ou não o poder, gerando uma mudança significativa em busca de uma maior equitatividade. Por outro lado, o poder, segundo Paulo Freire, constitui um aumento da conscientização e desenvolvimento da criticidade entre os marginalizados e oprimidos, suscitando maior capacidade de intervenção e controle das situações. Entre estes grupos marginalizados situa-se o segmento do idoso e, nesta nova postura, os idosos serão capazes de desempenhar um papel mais ativo, fortalecendo suas habilidades e assumindo a postura de protagonistas legítimos do próprio desenvolvimento (2003).

Os idosos na sociedade brasileira são considerados desempoderados porque são vitimizados culturalmente, resultado da vulnerabilidade reforçada por preconceitos e estereótipos negativos relativos à velhice. Entretanto os idosos organizam-se e mobilizamse para adquirir maior reconhecimento social, e assim passam constituírem um desafio às estruturas existentes.

O conhecimento passa a ser um instrumento eficiente e necessário para o empoderamento, em especial, para os idosos, na tentativa de superar os desequilíbrios sociais. As universidades ocupam grande parcela de responsabilidade diante da tarefa de educar. Embora cada uma destas entidades possua sua especificidade, não exclui a 
existência de diretrizes gerais, incluindo aquelas expressas em leis, que permeiam as ações universitárias, restritas ao próprio contexto histórico social.

Há um consenso quase unânime no sentido de se conferir à universidade a função de produzir e de difundir conhecimentos. Existe também uma aceitação válida, para a maioria dos países, de que é nela que se pode ter contato sistemático com a cultura universal (WANDERLEY, 1988).

Há a necessidade de repensar constantemente a universidade brasileira, conhecendo-se sua trajetória histórico-social, consolidando sua identidade, adequada à realidade nacional, constituindo-se em lugar privilegiado para o conhecimento da cultura universal e as várias ciências, criando e divulgando o saber, formando de maneira sistemática e crítica, profissionais, técnicos e intelectuais de nível superior engajados ativamente no processo sociocultural e político da sociedade brasileira.

Ressalta-se, então, que a extensão como uma das finalidades básicas da universidade, encerra em si grande complexidade, assim, redefine conteúdos de programas e cursos, reorienta pesquisas, oferece prestação de serviços profissionais redescobrindo o sentido a ser dado à ciência e ao conteúdo da formação profissional.

Toda ação extensionista, deve ser considerada num movimento horizontal, articulado ao ensino e à pesquisa, resultando num processo qualitativo de ações que objetivam contribuir significativamente para o desenvolvimento da comunidade, nos mais diversos âmbitos.

Castro $(2004$, p.14) afirma que a extensão "se coloca como um espaço estratégico para promover práticas integradas entre as várias áreas do conhecimento". No desempenho da função extensionista, a universidade atua como agente facilitador do desenvolvimento da educação, busca contribuir para o fortalecimento dos grupos sociais desempoderados, como os idosos, e, consolida ações para que a transformação social seja possível.

\section{RECUPERANDO A HISTÓRIA DA CRIAÇÃO DE UM ESPAÇO EDUCACIONAL PARA OS IDOSOS}

As diferentes iniciativas educacionais são elaboradas conforme as necessidades e exigências da sociedade. Assim, as representações sociais atribuídas à velhice em meados dos séculos XIX, significavam um rompimento das atividades laborais, implicando em uma mudança no estilo de vida e de costumes e, em decorrência, um distanciamento e isolamento social, o idoso volta-se mais para a família, reduzindo sua participação social e seu grupo de convivência, gerando um clima desalentador para a velhice.

Entretanto, os idosos que nasceram nas primeiras décadas do século $\mathrm{XX}$ vivenciaram uma realidade um pouco distinta daquela vivida por seus pais, na qual se pode registar a vida com satisfação depois da aposentadoria. Neste contexto, no qual os idosos tiveram maior visibilidade social, iniciou-se, embora lentamente, preocupações teóricas e práticas voltadas a esta faixa etária que variam desde oferecer melhores condições de vida, turismo, programas educacionais, políticas voltadas à pessoa idosa até a formação de profissionais para atender a esta faixa etária como também pesquisadores preocupados com esta temática.

Ao levantar o aspecto histórico percebe-se que ainda é muito recente o interesse por esta fase da vida que, somente em 1962 recebe a designação de "terceira idade".

Este termo foi proposto por Huet na revista Informations Sociales, que dedicava este número específico aos aposentados.

Os Estados Unidos e a França são os primeiros países a oportunizarem um espaço educacional para idosos. Tais experiências educacionais remontam a 1970 e refletem a preocupação com o envelhecimento populacional de ambos os países. 
Nos EUA a primeira experiência educacional para idosos aconteceu no século XVIII, tendo como princípio educativo o desenvolvimento da cidadania. Segundo Cachioni (1999, p.113-140), a educação religiosa assumiu uma orientação política e cívica à medida que "a capacidade para ler e escrever era desenvolvida para que todos os indivíduos adultos pudessem participar das decisões da nação e recebessem orientações religiosas, através da leitura e do entendimento da Bíblia".

O presidente Benjamin Franklin (em 1727) foi um dos precursores na criação de atividades educacionais para adultos e idosos nos Estados Unidos. Foi organizado um grupo denominado Junto, composto por adultos e idosos e durante trinta anos discutiram semanalmente questões relativas à sociedade. Já no século XIX, nasceu Luceum, com o objetivo de transmitir conhecimentos para habitantes de municípios rurais. Consistia em um programa educacional para adultos e para idosos. Concomitante foi criado o Chautauqua voltado para desenvolver atividades artísticas, tendo a música e o teatro como as principais atividades desenvolvidas nos espaços de diversas igrejas (CACHIONI, 2003).

Na década de 1950, a Universidade de Chicago e a Universidade de Michigan preocupadas com o envelhecimento da população, ofereceram cursos de preparação para a aposentadoria e nas décadas seguintes foram criados programas de treinamento para o trabalhador idoso, expandido também as pesquisas e produções científicas na área da gerontologia, difundindo sensivelmente os conhecimentos nesta área.

A primeira experiência registrada na área de educação foi criada na França, em 1960, chamada de Universidade de Tempo Livre, as quais são consideradas precursoras das Universidades da Terceira Idade, com o objetivo primeiro de preencher o tempo livre das pessoas idosas e aposentadas, oferecendo diferentes atividades culturais e lúdicas.

Também foi na França que em 1973, Pierre Vellas fundou a primeira Université $d u$ Troisième Âge (UTA) e segundo o próprio criador objetivava uma maior participação do idoso, incentivo à sociabilidade, gosto pela vida e com isto a busca de uma mudança na representação social que a sociedade atribuía à velhice.

De acordo com Palma (2000),

\section{Objetivos da criação da UTA}

\begin{tabular}{|c|c|c|}
\hline $\begin{array}{c}\text { Promover o } \\
\text { protagonismo das } \\
\text { pessoas idosas, } \\
\text { assim como lhes } \\
\text { oferecer } \\
\text { alternativas para } \\
\text { melhoria da } \\
\text { qualidade de vida. }\end{array}$ & $\begin{array}{c}\text { Colocar a } \\
\text { universidade a } \\
\text { serviço dos idosos, } \\
\text { possibilitando } \\
\text { maior participação } \\
\text { na vida social sem } \\
\text { discriminação pela } \\
\text { idade. }\end{array}$ & $\begin{array}{c}\text { Aprofundar as } \\
\text { pesquisas } \\
\text { gerontológicas, nas } \\
\text { quais os idosos } \\
\text { sejam } \\
\text { investigadores e } \\
\text { investigados. }\end{array}$ \\
\hline
\end{tabular}

Figura 2. Objetivos da criação da UTA

Fonte: Palma, 2000.

A UTA oferecia um programa educacional às pessoas idosas, visavam possibilitar uma maior inserção e preparação dos idosos para que se "(re)insiram na sociedade $e$, se necessário, intervenham em seus problemas"(PALMA, 2000, p.53). 
Outro ponto relevante volta-se para a importância dada à pesquisa, visando avanços na qualidade de vida dos idosos de modo geral, não apenas dos alunos das UTA.

Como tentativa de superar a discriminação e marginalização que os idoso sofriam, e pode-se ver que ainda sofrem, preocupou-se com o esboço de uma nova imagem da pessoa idosa, estimulando os idosos a desenvolverem atitudes de participação na vida social, econômica, política e cultural, e, concomitantemente, também possibilitar um maior relacionamento entre as gerações.

O espaço criado para os idosos nas universidades proporcionavam atividades ocupacionais e lúdicas, porém, ofereciam condições para o autodesenvolvimento e atualização, através de um espaço de compartilhamento de experiências e saberes acumulados pelos mesmos, permitindo a reflexão entre os pares na busca de rupturas de estigmas e estereótipos negativos, sem fundamentação teórica, em detrimento de um novo idoso, mais participativo e inserido socialmente, diminuindo o impacto ocasionado pelo envelhecimento e as mudanças rápidas que aconteciam em todas as sociedades.

As Universidades Abertas a Terceira Idade foram se disseminando pela Europa e América. Com a evolução da UTA, em 1980, com um perfil diferenciado dos alunos, com maior escolaridade, de acordo com Palma (2000, p.58), os eixos participação, autonomia e integração fundamentavam a organização das UTA. "Os participantes deixavam a posição de simples consumidores para serem produtores de conhecimento na medida em que participam das pesquisas universitárias"(PALMA, 2000, p.58). Assim, os alunos passaram a desenvolver um papel ativo nas pesquisas universitárias.

Basicamente podem ser considerados dois modelos de universidades para a terceira idade: o francês e o inglês, relacionando-os com os dois países considerados precursores nas ofertas educativas para os idosos.

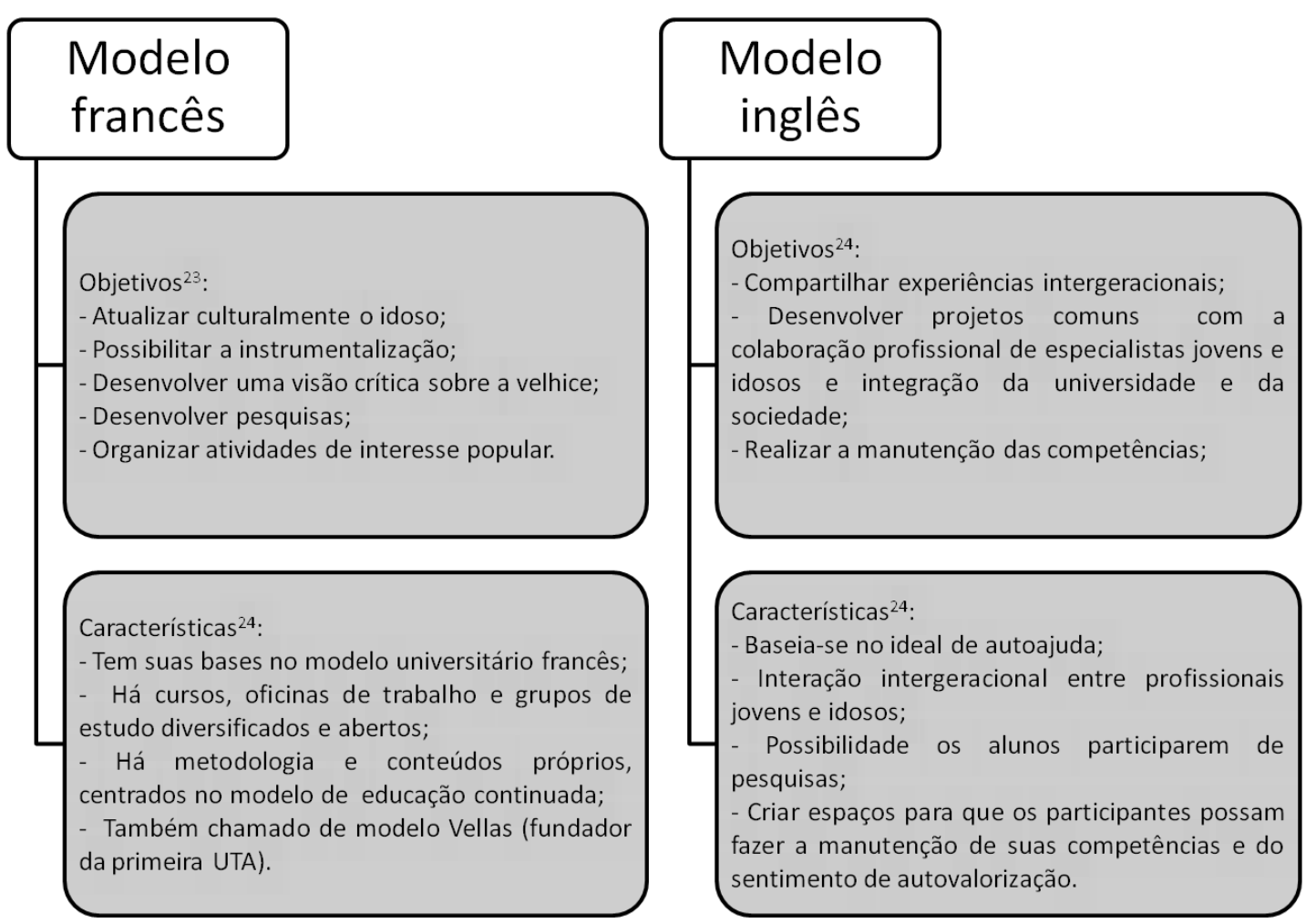

Figura 3. Modelos de universidades para a terceira idade

Fonte: Cachioni ,1998; Pacheco,2003. 
Esses dois modelos foram se disseminando por todo o mundo, inclusive no Brasil, sofrendo modificações conforme as necessidades locais, mas tendo como princípio maior, oferecer um espaço educativo, oportunizando o enriquecimento cognitivo, integração de conhecimentos, relacionamento intergeracional, elevação da autoestima e valorização da pessoa idosa.

Diante da demanda demográfica brasileira com o envelhecimento real e cumprindo com a legislação brasileira, em especial com o Estatuto do Idoso, reforçada pelas funções que são atribuídas às universidades: ensino, pesquisa e extensão, são oferecidos pelas Instituições de Ensino Superior os projetos/cursos de extensão como formas alternativas de atendimento ao idoso e também aos indivíduos que vão envelhecer, visando além de uma valorização, uma maior conscientização da sociedade em geral a respeito do processo de envelhecimento da população no país.

\section{AS UNIVERSIDADES ABERTAS NA SOCIEDADE BRASILEIRA: UMA REALIDADE}

As Universidades Abertas para a Terceira Idade (UATI) tem sido criadas nas diferentes universidades pelo mundo como uma modalidade da educação não-formal e educação permanente ao mesmo tempo que instrumentaliza o idoso com conhecimentos, informações, possibilitando e legitimando o exercício pleno da cidadania.

Estas UATIs caracterizam-se pelo encontro de gerações, a não-obrigatoriedade de frequência, a ocorrência de ações e experiências em espaços e tempos mais flexíveis, não restritos aos fixados por órgãos reguladores.

Segundo Gohn (2006) a educação não-formal representa várias dimensões, como a aprendizagem dos direitos numa perspectiva política, desenvolvimento de potencialidades, exercício de práticas comunitárias e sociais, aprendizagem que capacite para uma leitura de mundo, transmissão de informações, como também a formação política, social e cultural. A educação não-formal acontece em compartilhamento de experiências, em espaços e ações coletivas e cotidianas.

Nesta perspectiva da educação não-formal, as UATI buscam "oferecer possibilidades de experiências e vivências para que o público faça novas escolhas e opções pessoais e sociais [...]" (SILVA, 2006, p.9), além de oferecer conhecimentos, informações dentro de uma perspectiva de educação permanente.

Ao se pensar a educação como uma ação permanente e que o processo de aprendizagem ocorre durante toda a vida do homem, não evidencia apenas uma evolução do pensamento pedagógico, trata-se de uma necessidade de constante atualização num ambiente globalizado onde as mudanças são rápidas e contínuas, permitindo que o homem evolua segundo estes preceitos (OLIVEIRA, 1999).

Fundamentada na educação permanente, a educação para o idoso espalha-se rapidamente pelo mundo e chega ao Brasil na década de 1980, período no qual a Universidade Estadual de Ponta Grossa desenvolve Seminários, Cursos e encontros na área de educação, destinados a pessoas idosas da comunidade.

A educação é considerada como um direito fundamental, que está incluso em algumas políticas públicas destinadas para as pessoas idosas, todavia ainda não existe nenhuma política que referencie exclusivamente a educação para esse público.

Nos anos 1980, surge a "Federação dos aposentados" que inicia em território nacional uma luta em favor de melhores condições aos aposentados, e, estes conseguem pequenas modificações e acréscimos a Constituição de 1988 , com a finalidade de garantir melhor assistência aos idosos. 
Dentro da perspectiva de educação permanente e sendo a universidade um lugar por excelência para o aprimoramento, a pesquisa, a busca do conhecimento e também a democratização do saber, timidamente surge em seu âmago um espaço educacional para os idosos. As universidades ampliam sua função social, "buscando integrar aqueles que se encontram à margem do processo de desenvolvimento" (OLIVEIRA, 1999).

Segundo Oliveira (1999) os primeiros grupos constituídos por idosos se formaram em 1960, como Grupos de Convivência, cujo projeto visava principalmente o lazer, sendo que o Serviço Social do Comércio (SESC) desde esta época já desenvolvia programas de atendimento não institucional a pessoas idosas. Seus cursos concentravam-se em artesanato, canto, ginástica, pintura e lazer em geral.

Em 1970, surgiram as escolas abertas para a terceira idade:

Projeto baseado nas experiências francesas, direcionado para um público mais qualificado em termos educacionais já que oferecia, em seus módulos, programas de preparação para a aposentadoria, informações sobre aspectos biopsicossociais do envelhecimento e atualização cultural, além das atividades físicas e complementação sóciocultural. Esse programa sustenta-se numa proposta de Educação permanente e busca o desenvolvimento de potencialidades, de novos projetos de vida, estimulando a participação ativa do idoso e sua contribuição para a resolução de problemas em sua família e na comunidade (PALMA, 2000, p.71).

O pioneirismo do SESC não se limita a oferecer atividades para as pessoas com mais de cinquenta anos, mas também se volta para a formação de recursos humanos e ampliação do conhecimento gerontológico em eventos e cursos.

$\mathrm{O}$ envelhecimento humano passa a ser tratado na esfera política e transforma-se numa questão social e não mais numa questão puramente doméstica, porém ainda de forma tímida e insuficiente diante da demanda apresentada.

No ano de 1961 é fundada a Sociedade Brasileira de Geriatria e Gerontologia, entidade que se dedicava "[...] aos debates sobre o estudo e o tratamento das enfermidades e transtornos da idade avançada" (LOPES, 2000).

No Brasil, surgem as primeiras iniciativas educativas voltadas ao idoso em diferentes instituições universitárias, voltadas para o ensino, saúde e lazer.

Em 1982 foi fundado o Núcleo de Estudos da Terceira Idade na Universidade Federal de Santa Catarina que realizava estudos e divulgação de conhecimentos geronológicos, com a preocupação de formar recursos humanos e buscar uma maior visibilidade para o idoso na sociedade.

$\mathrm{Na}$ Universidade Federal de Santa Maria foi organizado em 1984 o Projeto Grupos de Atividades Físicas para a Terceira Idade, oferecendo diferentes atividades físicas para a pessoa idosa o que possibilita uma melhoria nas condições físicas e uma melhor qualidade de vida.

O Núcleo de Assistência ao Idoso foi criado no final da década de 1980 na Universidade Estadual do Rio de Janeiro, com a participação de profissionais de diferentes áreas de conhecimentos e posteriormente originou a Universidade Aberta à Terceira idade.

Entretanto, os projetos e cursos voltados a essa faixa etária no Brasil tiveram sua proliferação mais acentuada a partir de 1990, quando inúmeras universidades brasileiras abriram um espaço educativo para o idoso.

Entre as Universidades pode-se citar: A Pontifícia Universidade Católica de Campinas, em 1990, Universidade de Passo Fundo (RS), em 1991, Universidade 
Estadual de Ponta Grossa (PR), em 1992, Universidade Metodista de Piracicaba(SP), em 1992, Universidade de São Paulo, em 1995.

Embora com modelos e organização distintas, os cursos e projetos oferecidos pelas universidades brasileiras possuem o sujeito idoso como foco central das atividades e a valorização do idoso, melhoria da condição de cidadania e qualidade de vida como objetivo.

Essas diferentes iniciativas surgiram muito antes da sociedade política e civil perceber a necessidade da elaboração de politicas públicas voltadas para a pessoa idosa.

Muitas assembleias foram realizadas, em nível mundial, voltados ao estudo do envelhecimento.

Entre as Assembleias, destaca-se a Assembleia Mundial sobre o Envelhecimento, a qual foi realizada em Viena, no ano de 1982. Desta assembleia resultou um plano internacional sobre envelhecimento, o qual foi considerado por muitos estudiosos o primeiro documento de nível mundial, o qual destacava a situação da população idosa e trouxe metas como atender às preocupações e necessidades especiais das pessoas de mais idade, e fomentar uma resposta internacional adequada aos problemas do envelhecimento, estabelecendo um nova ordem econômica e o desenvolvimento de atividades de cooperação técnica, principalmente entre os países em desenvolvimento (ONU, 1982). Desta Assembleia resultou o Plano de Viena.

A segunda Assembleia foi realizada em Madri em 2002, 20 anos após a primeira assembleia. Também resultou desta um plano internacional sobre o envelhecimento, conhecido como Plano de Madri. Nesta assembleia foi aprovado um outro documento, uma Declaração Política, na qual todos os países signatários comprometem-se em cumprir as metas do Plano de Madri em até 25 anos. O referido Plano traz três prioridades: necessidade das sociedades ajustarem suas políticas e instituições para que a crescente população idosa, promoção da saúde e bem-estar para todo o ciclo de vida e a criação de contextos propícios e favoráveis, que promovam políticas orientadas para a família e a comunidade como base para um envelhecimento seguro (MADRI, 2002).

A Conferência Mundial de Educação para Todos realizada em Dakar (2000), reafirmou a necessidade e a importância da educação em todas as idades. Recomendou-se novamente a necessidade de assegurar o direito de educação, para que haja a equidade de acesso a uma aprendizagem apropriada, que desenvolva habilidades e que possibilite programas de formação para a cidadania (ONU, 2000).

Percebe-se que existe um grande avanço com relação a preocupação da educação ao longo da vida, incluindo aqui o idoso. Assim, são criados projetos/cursos na modalidade de educação não formal caracterizando-se pelo encontro de gerações, a não obrigatoriedade de frequência, a ocorrência de ações e experiências em espaços e tempos mais flexíveis não restritos aos fixados por órgãos reguladores (SILVA, 2006).

Os projetos/cursos oferecidos para o idoso não devem assumir uma conotação meramente assistencialista, mas sim orientam-se para estimular o idoso a desenvolver atitudes de participação na vida social, econômica, política e cultural, promovendo também a solidariedade entre as gerações e a troca de experiências entre jovens e idosos, permitindo o desenvolvimento pessoal e coletivo e sua reinserção social. Portanto, o foco principal deve ser promover a participação, autonomia e integração do idoso para uma melhor qualidade de vida.

É premente a necessidade da educação, a medida que, pelo conhecimento e informações, irá instrumentalizar o idoso, possibilitar a compreensão da realidade em que está inserido, emergindo um sujeito crítico, reflexivo que reivindique seus direitos e usufrua de cidadania plena. 
De acordo com Mosquera (1975, p.74), a "educação permanente é universal no seu caráter e essencial à completa democratização da aprendizagem, caracterizada pela sua flexibilidade e diversidade em conteúdos, apreendendo elementos, técnicas e finalidades abertas ao tempo e ao espaço".

A concepção de educação permanente, na modalidade não formal estimulou e fundamentou muitos cursos/ programas voltados para os idosos em diferentes instituições brasileiras. Essa disseminação de ações educativas para os idosos deve-se ao fato por um lado do envelhecimento da população, o que está refletida na demografia do nosso pais e, por outro lado, o que está estabelecido na legislação brasileira como a educação direito de todos - Constituição de 1988 e Estatuto do Idoso.

Entre os cursos desta natureza cita-se a UATI na UEPG, criado em 1992, como um projeto tímido mas depois dos 24 anos de funcionamento tem grande reconhecimento acadêmico e social, e atualmente se estrutura como Programa.

A UATI, com abordagem multidisciplinar, reflete sobre diferentes dimensões do processo de envelhecimento e da velhice, elege como prioridade a valorização do idoso e atualmente possui 500 alunos matriculados.

A UATI pauta-se nos seguintes objetivos: valorizar o idoso; possibilitar a aquisição de conhecimentos, informações e por conseguinte a atualização do idoso; proporcionar uma melhor qualidade de vida para o idoso, tornando-o mais ativo, alegre, participativo e integrado à sociedade; ampliar a convivência e as relações intergeracionais, propiciar a elevação da autoestima do idoso, o desenvolvimento das potencialidades intelectuais; respeitar a individualidade, a sabedoria e as experiências do idoso.

A UATI estrutura-se em quatro grandes eixos articuladores, nos quais baseiam-se as disciplinas oferecidas, são eles: saúde, nutrição e qualidade de vida, educação, cultura e arte; educação, esporte e lazer; direito, empoderamento e cidadania.

Distribuídos nos eixos são oferecidas disciplinas teóricas e práticas, totalizando 240 horas, ao longo de três semestres letivos, seguindo o calendário universitário.

São oferecidas disciplinas obrigatórias, nas diferentes áreas de conhecimento, também oferecidas disciplinas optativas que atualmente são em número de treze.

Entre essas disciplinas optativas, estão as que se voltam para aquisição de conhecimentos e desenvolvimento intelectual como o inglês, o espanhol e informática.

Entre as disciplinas que possibilitam o desenvolvimento de habilidades artísticas encontram-se a pintura em tela e o artesanato. Referente a expressão corporal, sensibilidade, música, canto e interpretação são oferecidas as disciplinas de Teatro e o Grupo de Seresta Reviver.

As atividades físicas também são evidenciadas através das disciplinas de natação e hidroginástica, dança de salão, alongamento e relaxamento, dança circular, caminhada e atividades esportivas.

Existe também a disciplina de Teatro e o Grupo de Seresta Reviver.

O currículo da UATI é organizado de maneira interativa, conforme as opções dos próprios idosos, sendo as disciplinas teóricas de caráter obrigatório e as práticas de caráter optativo.

O Estágio realizado na UATI, constitui o último semestre letivo do Curso, no qual são programadas atividades como visitas a diversas instituições, entre elas: hospitais, asilos, escolas, centros de convivência de idosos. São elaborados projetos pelos idosos sob a orientação de um professor e, em seguida, vão a campo implementar as atividades planejadas.

Os alunos recebem certificado de conclusão de curso por ocasião da formatura que acontece no final do terceiro semestre letivo, na qual participam autoridades universitárias e da comunidade. 
Embora os Projetos/ Cursos/Programas apresentem diferenças em sua organização, currículo, docentes buscam fundamentalmente a melhoria da qualidade de vida, elevação da auto-estima do idoso, reconhecimento do idoso na sociedade como um protagonista de sua história e ator social, sendo atualizado e instrumentalizado com conhecimentos e informações necessárias para o exercício pleno da cidadania.

As UATI promovem indiretamente um movimento social protagonizado pelos idosos e influenciam toda a sociedade principalmente no sentido de reflexão sobre o papel dos idosos na sociedade capitalista, as mudanças e superações dos estereótipos e estigmas negativos atribuídos à esta faixa etária e que hoje, diante da realidade, aos poucos são substituídos por uma visão mais otimista, integradora e de inclusão.

\section{CONSIDERAÇÕES FINAIS}

As políticas públicas brasileiras, voltadas especificamente para o idoso, prescrevem condições para a melhoria da qualidade, implementadas devido ao aumento significativo do número de idosos na população brasileira.

Dentre as muitas ações prescritas, em especial no Estatuto do Idoso (Lei 10.741/03), destaca-se a importância de instituições de ensino oferecerem projetos/cursos para esta faixa etária.

Desta maneira, os projetos/cursos têm se disseminado rapidamente pelo país, para além de responderem a um princípio legal, estimulam mais estudiosos para refletirem sobre esta fase da vida, com pesquisas científicas.

Diferentes iniciativas surgem na área da educação voltadas para o idoso, pautadas em promover o bem estar, integrando como cidadãos partícipes e produtivos na sociedade, são as Universidades Abertas para a Terceira Idade.

Os modelos de UATI são variados quanto a organização, duração, metodologia, estrutura, características dos alunos, professores, mas a maioria com o objetivo comum de promover a interação e integração, dar maior visibilidade ao idoso e possibilitar a ruptura de preconceitos culturalmente instituídos.

Em especial a UATI/UEPG apresenta benefícios incontestáveis aos idosos que a frequentam, tem contribuído para o resgate da cidadania do idoso, oportunizando diferentes atividades e possibilidades de melhoria na qualidade de vida, empoderamento, exercício da cidadania e autonomia para se inserir ativamente na sociedade.

A somatória de esforços da sociedade política e civil na visão de totalidade, reveste-se do sonho de superar os estereótipos negativos, preconceitos relacionados aos idosos, situações de violência e vulnerabilidade a que esta faixa etária está exposta, em busca de desenhar uma nova representação social do idoso, com respeito as suas experiências, sabedoria, potencial de crescimento e aprendizagem, para um novo paradigma de velhice.

\section{Referências}

BRASIL. Lei no 10741 de 3 de outubro de 2003. Dispõe sobre o Estatuto do Idoso. Diário Oficial da União 2003; 3 out.

Lei ${ }^{\circ} 8842$ de 4 de janeiro de 1994. Dispõe sobre a Política Nacional do Idoso. Diário Oficial da União 1994; 4 jan. 
CACHIONI, M. Envelhecimento bem sucedido e participação numa universidade para a terceira idade: a experiência dos alunos da Universidade São Francisco [dissertação] Campinas, Faculdade de Educação da Unicamp; 1998.

Quem educa os idosos? Um estudo sobre professores de universidades da terceira idade. Campinas: Alínea; 2003.

CASTRO, L.M.C. A universidade, a extensão universitária e a produção de conhecimentos emancipadores. Anais da 27 Reunião Anual da ANPED; 2004 Out; Caxambu.

FREIRE, P. Educação e Mudança. Rio de Janeiro: Paz e Terra; 1979.

Política e educação. São Paulo: Cortez; 1997.

GADOTTI, M. A educação contra a educação. Rio de Janeiro: Paz e Terra; 1984.

KLEBA, ME, WENDAUSEN, A. Empoderamento: processo de fortalecimento dos sujeitos nos espaços de participação social e democratização política. Saúde Social, 2009; 18 (4): 733-743.

LOPES, A. Os desafios da gerontologia no Brasil;. Campinas: Alinea, 2000.

MARTÍN GARCÍA, AV. Educación y envejecimiento. Barcelona: PPU; 1994.

MOSQUERA, JJM. Educação: novas perspectivas. Porto Alegre: Sulina; 1975.

NERI, AL, CACHIONI, M. Velhice bem-sucedida e educação. In: NERI, A L; DEBERT, GG. Velhice e sociedade. Campinas: Papirus; 1999. p. 113-140.

OAKLEY, P, CLAYTON, A. Monitoramento e avaliação do empoderamento. Tradução de Zuleika Arashiro e Ricardo Dias Sameshima. São Paulo, Instituto Pólis; 2003.

OLIVEIRA, R.C.S. Terceira Idade: do repensar dos limites aos sonhos possíveis. São Paulo: Paulinas, 1999.

ONU. Informe de laq Primera Asamblea Mundial sobre El Envejecimiento - Viena. Nova York:ONU, 1982.

ONU. Informe de La Segunda Asamblea Mundial sobre El Envejecimiento - Madrid. Nova York:ONU, 2002.

PACHECO, JL. As universidades abertas à terceira idade como espaço de convivência entre gerações. In: SIMSON, ORMV, NERI, AL, CACHIONI, M. As múltiplas faces da velhice no Brasil. Campinas: Alínea; 2003.

PALMA, LTS. Educação permanente e qualidade de vida: indicativos para uma velhice bem-sucedida. Passo Fundo: UPF; 2000.

PETERSON, AD. Educational Gerontology: The State of the Art. Educational Gerontology 1976; 1(2): 61-73. 
PINTO, AV. Sete lições sobre a educação de adultos. São Paulo: Cortez; 1989.

SAFONS, MP, PESSOA, IL. Educação, esporte, cultura e lazer para as pessoas idosas. In: CNDI. Avaliação nacional dos direitos da pessoa idosa. Texto base. Brasília: Secretaria Especial dos Direitos Humanos; 2008.

SAVIANI. D. Pedagogia histórico-crítica. Campinas: Autores Associados; 1991.

SILVA, R. Fundamentos teóricos e metodológicos da pedagogia social no Brasil. Anais do $1^{\circ}$ Congresso Internacional de Pedagogia Social, 2006, São Paulo.

USC. Davis School of Gerontology. Disponível em: www.usc.edu/dept/gero.

VASCONCELOS, EM. O poder que brota da dor e da opressão: empowerment, sua história, teorias e estratégias. São Paulo: Paulus; 2001.

WANDERLEY, LE. O que é universidade. São Paulo: Brasiliense; 1988.

ZAYAS, EL. O Paradigma da Educação Continuada. Porto Alegre: Penso; 2012.

\footnotetext{
${ }^{1}$ Pedagoga. Gerontóloga. Pós-doutora em Educação. Professora Permanente do Programa de Pós Graduação Mestrado e Doutorado em Educação na Universidade Estadual de Ponta Grossa. Coordenadora da Universidade Aberta para a Terceira Idade na UEPG. E-mail: $\underline{\text { soliveira13@uol.com.br }}$

${ }^{2}$ Pedagoga. Mestre em Educação. Doutoranda em Educação. Professora da Universidade Estadual de Ponta Grossa. Professora da Universidade Aberta para a Terceira Idade na UEPG. E-mail: paola_scortegagna@hotmail.com

3 Advogada. Mestre em Ciências Sociais Aplicadas. Doutoranda em Ciências Jurídicas. Coordenadora e Professora da UNOPAR/Ponta Grossa. Professora da Universidade Aberta para a Terceira Idade na UEPG. E-mail: flasoliveira@uol.com.br
}

Recebido: $\quad$ setembro-15 Aprovado: outubro-15 